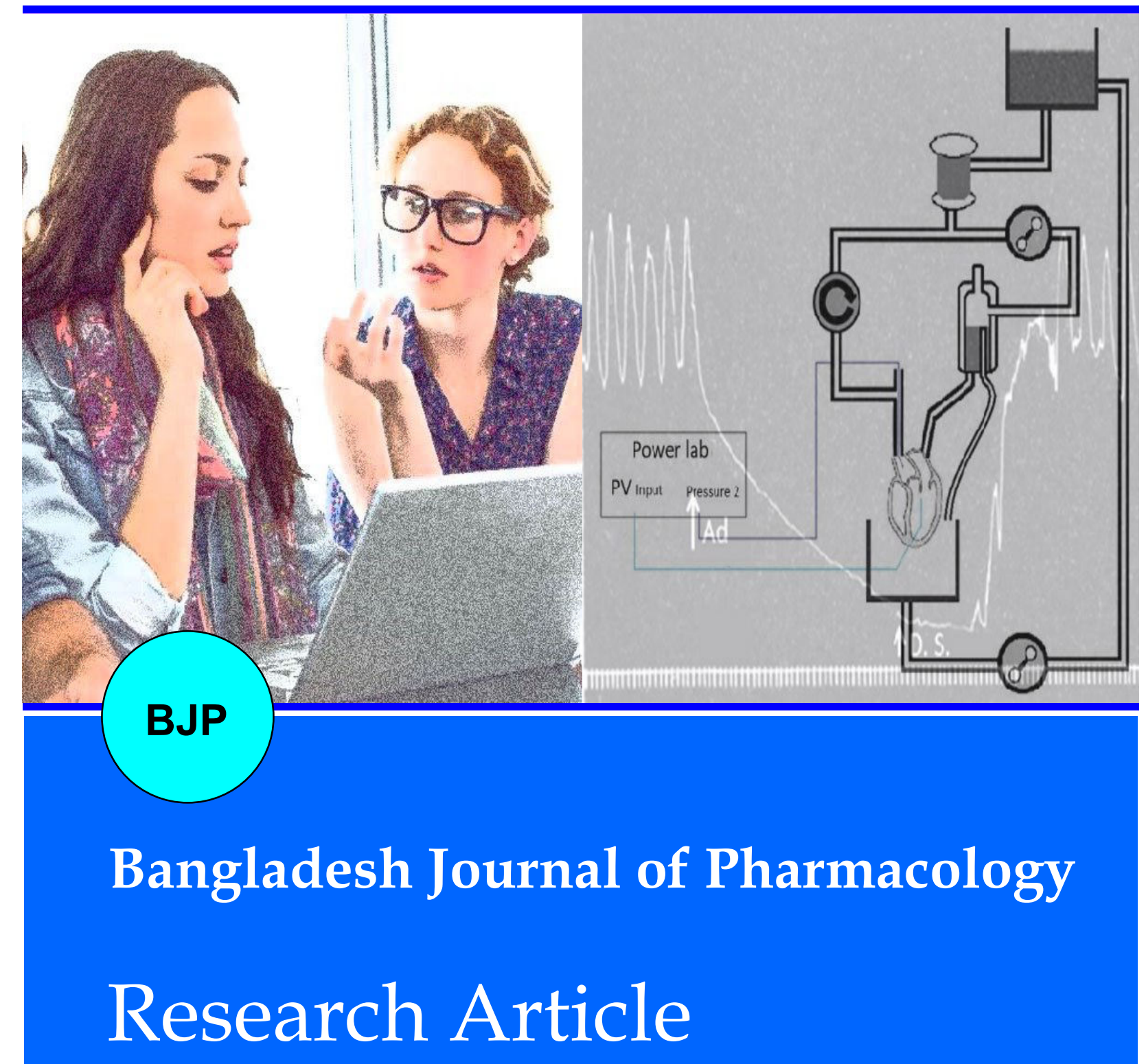

Involving postgraduate medical students in pharmacology practical classes by e-learning 


\title{
Involving postgraduate medical students in pharmacology practical classes by e-learning
}

\author{
Asma Akter Abbasy and Mir Misbahuddin \\ Department of Pharmacology, Faculty of Basic Science and Paraclinical Science, Bangabandhu Sheikh Mujib \\ Medical University, Shahbag, Dhaka, Bangladesh.
}

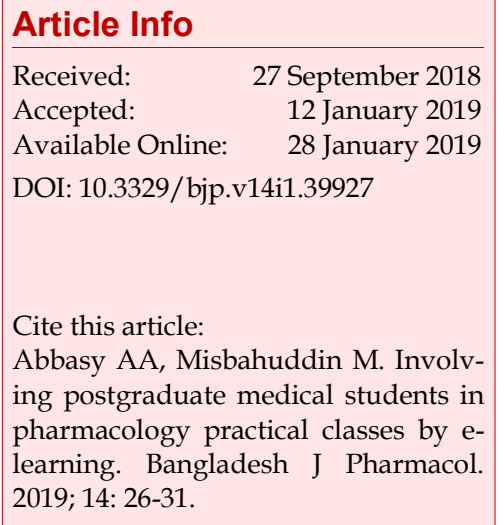

\begin{abstract}
The aim of the present study was to evaluate the effectiveness of e-learning (virtual class) in achieving procedural knowledge necessary to conduct practical class in the laboratory. In this study, teaching modules were prepared on eight selected topic related to pharmacology laboratory works. Virtual classes were conducted among the postgraduate MD students $(n=26)$ of this department. To know the existing procedural knowledge pre-test was taken before the classes and to evaluate the effectiveness of virtual class, a post-test was carried out seven days later. To get the feedback from students, two additional questionnaire surveys were done. The performance of each student improved in the post-test in comparison to the pre-test. Most of the students mentioned that virtual class was easier in comparison to face to face class. But they preferred combination classes to learn procedural knowledge.
\end{abstract}

\section{Introduction}

In Bangladesh, there are about 93 medical colleges at present (Directorate General of Health Services, 2015). Students are getting more interest to build their career in medical science. Almost 8,925 new students are getting admitted each year. So, there is pressure on the limi -ted number of teachers in different medical colleges.

Pharmacology is an important discipline in medical course. For medical practitioners, it is an important aspect as they need to apply the knowledge and skill of pharmacology to manage patient (Tse et al., 2007). It has been noticed that most of the MBBS students faced trouble during patient management due to deficiencies in achieving pharmacological practical knowledge although they felt confident with regard to knowledge and skill about diagnosing a patient (Prince et al., 2004). So, there is pressing need for the medical graduates to be fully prepared to take the responsibilities of prescribing and to be able to respond to continual inevitable rapid changes in therapeutics (Maxwell and Walley, 2003).
Considering three teachers at the level of Assistant Professor, Associate Professor, and Professor in each medical college, the required teachers in 93 colleges should be 279 , but the number of teachers is less than the requirement. It is not possible to provide uniform teaching to all medical colleges due to less number of personnel. There is a lack of interest and skilled manpower to conduct the practical class. There is also a shortage of equipment, chemicals, and books.

e-Learning (virtual class) is not a new approach to education in Bangladesh. Recently this learning has got a new dimension due to the application of computer and internet facilities. This technology is not applied in medical students of Bangladesh. The virtual class can be the best method of conducting classes to overcome the physical boundaries of the classroom and students would be able to do the class at a time of their own choice, without having to travel to anywhere (Kemp and Grieve, 2014). Some universities and colleges around the world offer online degree programs and courses, which give students the opportunity to access higher education from anywhere (The complete 
university guide, 2016). If we analyze the current development and visible trends to technology, it can be predicted that medical education is going to have an intense change in the future. So, there is a need for growing awareness about the use of innovative advanced educational technology to cope up with the changes (Benor, 2014).

The flexibility of the online virtual format is that mentoring is possible whenever it is mutually convenient. In an online virtual class, additional content like an additional background and question answering, all can be done simultaneously in the same class (Malanson et al., 2014). Thus, synchronous virtual class involves 'just in time' interactions between teachers and students (McBrien et al., 2009). It is also a useful distant learning tool as it is accessible to students at different locations (Martin and Parker, 2014).

Under the project of University Grants Commission, Bangladesh, there was an attempt to conduct virtual class from Bangabandhu Sheikh Mujib Medical University to other medical colleges of Bangladesh from 2011 to 2014 (web-based record). Those classes were on theory-based topics. The practical class can also be conducted through the virtual class. Therefore, this study was designed to conduct the virtual class on pharmacology practical for postgraduate medical students.

\section{Materials and Methods}

\section{Teaching module}

Teaching modules were prepared on eight topics, related to laboratory work in pharmacology. A PowerPoint presentation of about $30 \mathrm{~min}$ was prepared.

\section{PowerPoint presentation}

PowerPoint presentations were prepared in Microsoft Office PowerPoint 2010. Each presentation was divided into sections like introduction, objective, methods, and conclusion. Related articles and online information were used to prepare the teaching modules. Learning content and objectives were pre-validated by the supervisor.

\section{Devices}

A laptop with processor: intel core i3 CPU @ $2.40 \mathrm{GHz}$, RAM: 4 GB, system type: 64-bit operating system, graphic card: intel $\AA$ HD graphics 4000 with 15" monitor, a 3G Grameen phone USB internet modem with $1 \mathrm{Mbps}$ speed and a headphone were used.

\section{Software}

Online meeting software TeamViewer version 9 was used. TeamViewer is a proprietary computer software package for remote control, desktop sharing, online meetings, web conferencing and file transferring between computers. It can be used without charge by the non-commercial users.

\section{Conduction of classes}

Hands-on training of about two hours was given to the participant about the installation of TeamViewer software and participating online classes. Before conducting the class, necessary equipment like laptop, internet connection and TeamViewer software were pre -tested by practicing a sample virtual class. Classes were conducted on a particular date with a mutually convenient time. First $10 \mathrm{~min}$ was for the installation of software from the participant end and to check the sound system, next $30 \mathrm{~min}$ were for the presentation and the last $20 \mathrm{~min}$ was for question-answer session.

\section{Evaluation}

\section{Questionnaire validation}

Questionnaire were not validated according to the method available in the online due to time constraint (Methodspace, 2014).

\section{Questionnaire survey}

To carry out pre- and post-test, 10 questions were prepared on each teaching module using the online Survey Monkey software. The same questionnaire was used for both tests. In addition, two more questionnaire surveys were done to take the feedback from students on each teaching module and to know the knowledge they acquired at the completion of the class.

\section{Data collection procedure}

All data were collected from the free online Survey Monkey software, online survey creation and delivery tool.

\section{Data analysis}

This survey provided both quantitative and qualitative data. Quantitative data were analyzed using the online paired t-test calculator.

\section{Study population}

The purpose of the study was explained to the postgraduate MD students studying at this department and they agreed voluntarily to participate.

\section{Results}

\section{Comparison of pre- and post-test data}

In the pre-test, highest marks were 6.9 and 6.4 in the teaching module ' 1 ' and ' 2 ' respectively (Table I). The highest marks in the post-test were 8.9 and 8.7 in the teaching module ' 8 ' and ' 1 ' respectively.

The improvement in the performance of pre- and posttest was marked (4.8) in the teaching module No. 5. This change may be due to the less mark obtained in the 
Table I

Pre- and post-test results

\begin{tabular}{|c|c|c|c|c|c|c|c|}
\hline \multirow[t]{2}{*}{ Module } & & & & \multicolumn{2}{|c|}{$\begin{array}{l}\text { Average marks } \\
\text { obtained }\end{array}$} & \multirow[t]{2}{*}{ Change } & \multirow[t]{2}{*}{$\begin{array}{c}\mathrm{p} \\
\text { valuea }\end{array}$} \\
\hline & & & & Pre-test & Post-test & & \\
\hline 1 & Drug delivery to the lungs & Video & Question & 6.9 & 8.7 & +1.8 & 0.10 \\
\hline 2 & $\begin{array}{l}\text { Procedure to determine the effect of adrenaline on rat } \\
\text { uterus }\end{array}$ & Video & Question & 6.4 & 8.2 & +1.8 & 0.01 \\
\hline 3 & Mydriatic eye drop & Video & Question & 5.1 & 8.3 & +3.2 & 0.02 \\
\hline 4 & Tissue response to agonist & Video & Question & 4.2 & 8.2 & +4.0 & 0.01 \\
\hline 5 & $\begin{array}{l}\text { In vitro experiment on the animal heart using Langen- } \\
\text { dorff apparatus }\end{array}$ & Video & Question & 3.3 & 8.1 & +4.8 & 0.00 \\
\hline 6 & In vitro dissolution testing apparatus & Video & Question & 5.4 & 7.7 & +2.3 & 0.00 \\
\hline 7 & Spectrophotometric measurement of rifampicin & Video & Question & 4.5 & 7.0 & +2.5 & 0.02 \\
\hline 8 & Steps of giving a subcutaneous insulin injection & Video & Question & 5.7 & 8.9 & +3.2 & 0.01 \\
\hline
\end{tabular}

\section{Table II}

\section{Number of participants and dropout of students and questions}

\begin{tabular}{|c|c|c|c|c|c|}
\hline \multirow[t]{2}{*}{ Module } & \multicolumn{3}{|c|}{ Total participants present } & \multicolumn{2}{|c|}{$\begin{array}{l}\text { Total number of dropout } \\
\text { of questions attempted } \\
\text { by participants }\end{array}$} \\
\hline & Pre-test & During class & Post-test & Pre-test & Post-test \\
\hline 1 & 26 & 11 & 11 & 0 & 1 \\
\hline 2 & 21 & 13 & 13 & 3 & 0 \\
\hline 3 & 24 & 15 & 15 & 2 & 5 \\
\hline 4 & 18 & 11 & 10 & 3 & 4 \\
\hline 5 & 14 & 12 & 10 & 4 & 0 \\
\hline 6 & 16 & 11 & 9 & 0 & 0 \\
\hline 7 & 14 & 12 & 10 & 1 & 2 \\
\hline 8 & 13 & 10 & 9 & 2 & 0 \\
\hline Mean \pm SD & $18.3 \pm 4.9$ & $11.9 \pm 1.6$ & $10.9 \pm 2.1$ & 15 & 12 \\
\hline$P$ value & $\mathrm{A}=0.004, \mathrm{~B}=0.3$ & & & & \\
\hline \%Dropout of participants & 29.6 & 35 & 8.4 & & \\
\hline $\begin{array}{l}\text { \%Dropout from the total num- } \\
\text { ber of questions }\end{array}$ & & & & 1 & 1.4 \\
\hline
\end{tabular}

pre-test. The improvement in performance was lowest (1.8) in the module No. 1 and module No. 2. This may be due to the highest mark obtained in these two modules in the pre-test.

\section{Pre- and post-test dropout of students}

Table II shows the number of participants (mean \pm SD) attended during the pre-test, virtual class and post-test were $18.3 \pm 4.9$ (range: $13-26$ ), $11.9 \pm 1.6$ (range: 10-15) and $10.9 \pm 2.1$ (range: 9-15) respectively. There was a significant dropout of participants during the pre-test and virtual class $(p=0.004)$. However, the dropout of participants during the class and post-test were not significant $(p=0.3)$. That is, once they attended the virtual class, they participated actively in the post-test. This was the positive side of this study. Only a negligible number (around 1\%) of the total number of questions were dropped out.

\section{Discussion}

In most of the areas, the teaching-learning activity was found to be effective. On the other hand, the effectiveness was not equal or equivalent in all the modules under study. Regarding improvement in 
performance, 'In vitro experiment on the animal heart using Langendorff apparatus' module was found to be most effective as reflected by the maximum improvement between pre- and post-test status of learners. This is probably because of the fact that the participants had minimum existing knowledge on this issue and therefore, the interest among the participants was maximum and improvement was also high because of the difference. Whereas, 'Drug delivery to the lungs' and 'Procedure to determine the effect of adrenaline on rat uterus' modules were found least effective. This perhaps happened because of the high existing knowledge of the participants that had no learning gap to fill and the improvement was less. However, the actual reasons behind the difference in effectiveness among different modules are difficult to ascertain from this study.

There was a significant number of dropout of candidates appearing in pre-test from attending the class and therefore post-test. This could imply technology shyness among the general population to accept something which was new and unfamiliar to them. On the other hand, there was an insignificant number of dropout candidates attending the classes from appearing at the post-test. This indicates that the attending learners had explicitly expressed their interest in the method. Although in this study, the comparison was not made in the face to face and virtual class, participants already had their experience with face to face class. Therefore they had the capability to make a comparison between the two. It was found from the study that they preferred combining the two methods for more effective learning. This study explored the conformity of the class hour and the context as assessed from the number of slides. In general, the learners mentioned that the duration of the class was adequate and the numbers of slides were appropriate. It is not sure on what basis they had found their opinion. If learning needs were assessed beforehand this could form a basis to such an opinion. Short of that the opinions remain arbitrary.

In the perspective of the current development of Information and Communication Technology (ICT) including enhanced internet speed, the scope has been created to include ICT in distance learning in the form of virtual class. This has become more relevant in the perspective of a shortage of teachers in most of the basic science disciplines including Pharmacology. If successful this would open opportunity for expanding the teaching-learning process outside the conventional method among which face to face class is a prevalent and popular one. The success of any educational method depends on its effectiveness as well as familiarity and acceptance by both the provider and the audience. In this study, the teaching modules having been delivered from a distance over internet protocol, the effectiveness was assessed through a selfadministered online questionnaire survey. The learners' preferences were evaluated similarly through a separate questionnaire.

Among the technical aspects of ICT, availability of personal computers and internet connection along with its speed were considered to be important issues in promoting this kind of virtual learning. Unavailability of a personal computer or shared computer systems may be a deterrent to using this method universally. In this study, it was not however surveyed whether the participants had easy, convenient and continuous access to ICT tools. However, the dropout seen among the participants in the study could reflect a number to whom the ICT tools were not available at the appointed time of class but may also have other reasons to be discussed later.

Incorporation of technology in education is a new phenomenon in Bangladesh. We are habituated with face to face teaching-learning since childhood. The concept of virtual learning is still newer even to the postgraduate students. Though it is newer, this study revealed satisfactory effectiveness in case of virtual teaching-learning and learners' preference seems to be quite encouraging. At the national level, this technology has already been incorporated from primary school level, it is likely to become the game of the tomorrow's teaching-learning. Therefore, teachers should pay attention to incorporate distance learning in higher education and thus increase the scope of teachinglearning including more number of students. By this technology confinement of classroom can be opened up beyond its boundaries. The world is advancing day by day and there is a need to convey information to the increasing number of population in an easy and effective way. Therefore, to be ready to face future challenges in higher education, it necessary to work more in this particular direction. If the identification of limitations of this study and the way to overcome those limitations become possible, virtual teaching-learning would become the order of the day in near future.

The learning in medical education is expected to be flawlessly effective because the practices of the learners directly affect health and life, both of which are precious. It is not true only because of its long tradition but also because of the presence of the premier authority of teaching and learning as we call them teacher, in the classroom to undertake fact to face teaching-learning as well as make an impact on its effectiveness, face to face learning has advantages in terms of greater control over the learners. In this respect, virtual learning where the teacher is not present actually in the classroom has lesser control over learning. However, this can be generally overcome by the great fascination of learners for this modality in terms of their true advantages that can create greater learning ability. Though the people have such a general notion and trend that they feel ease in conducting a 
class face to face, slow and steady incorporation of virtual teaching-learning as well as action research in this direction can change the concept of general people about virtual class. From this study, it was found that virtual learning is effective in learning procedural knowledge in some selected topics. If this virtual platform becomes effective in learning procedural knowledge in undergraduate and postgraduate, it can be applied to Continuing Medical Education and training. It is good to know that people do prefer to conduct Continuing Medical Education and training from the place they concern because worldwide Continuing Medical Education is online based. But it is required to prove urgently and for sure that procedural learning can be done effectively using a virtual platform. If proven, it will open a vista of new prospect so that people on the study can conduct training from their working place and the learners receive them from their own workplaces.

A study conducted in the Psychology Department of the University of Tasmania, Australia revealed that there was no significant difference in the academic performance of students in face to face class and online classes (Kemp and Grieve, 2014). Virtual laboratory for conducting practical classes have already been introduced in different faculties of science like Physics (Finkelstein et al., 2005), Biology (Muhamad et al., 2010), Engineering (Rajendran et al., 2010), Chemistry (Bakar et al., 2013) and have been found to be effective. Though no similar study had been done before to evaluate the effectiveness of virtual presentation in achieving procedural knowledge, this is expected from the study that the new generation of students of Bangladesh will have the capability to cope and assimilate the newer technology as good as any developed country.

\section{Conclusion}

Teaching-learning in practical classes on pharmacology is effective.

\section{Ethical Issue}

A protocol was prepared according to the format provided by the Institutional Review Board (IRB) which was approved by the IRB of Bangabandhu Sheikh Mujib Medical University with a reference No. BSMMU/2015/6067. All the participants were informed about the objectives of the study and were encouraged to participate voluntarily. Verbal consent was taken from them.

\section{Conflict of Interest}

Authors declare no conflict of interest.

\section{References}

Bakar N, Zaman HB, Kamalrudin M, Jusoff K, Khamis N. An effective virtual laboratory approach for chemistry. Aust J Basic Appl Sci. 2013; 7: 78-84.

Benor DE. A new paradigm is needed for medical education in the mid-twenty-first century and beyond: Are we ready? Rambam Maimonides Med J. 2014; 5: 1-10.

Directorate General of Health Services (DGHS). Govt. Medical College Dental College and Private Medical College Dental College. Available at: http://www.dghs.gov.bd/images/

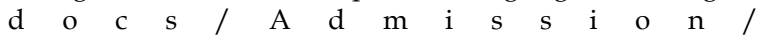
Govt.MC_Dental_and_Private_MC_Dental_College.pdf [Accessed on 3rd February 2016].

Finkelstein ND, Adams WK, Keller CJ, Kohl PB, Perkins KK, Podolefsky NS. When learning about the real world is better done virtually: A study of substituting computer simulations for laboratory equipment. Phys Rev Spec Top-Ph Educ Res. $2005 ; 1: 1-8$.

Kemp N, Grieve R. Face-to-face or face-to-screen? Undergraduates' opinions and test performance in classroom vs. online learning. Front Psychol. 2014; 5: 1-11.

Malanson K, Jacque B, Faux R, Meiri KF. Modeling for Fidelity: Virtual mentorship by scientists fosters teacher self-efficacy and promotes implementation of novel high school biomedical curricula. J Med Teach. 2014; 9: 1-23.

Martin F, Parker MA. Use of synchronous virtual classroom: Why, Who \& How? MERLOT J Online Learning Teaching. 2014; 10: 192-210.

Maxwell S, Walley T. Teaching safe and effective prescribing in UK medical schools: A core curriculum for tomorrow's doctor. Bri J Clin Pharmacol. 2003; 55: 496-503.

McBrien JL, Jones P, Cheng R. Virtual spaces: Employing a synchronous online classroom to facilitate student engagement in online learning. Int Rev Res Open Dis Learning. 2009; 10: 1-17.

Methodspace. Validating a questionnaire. Available at: http:// www.methodspace.com/profiles/blogs/validating-aquestionnaire [Accessed on 10 $0^{\text {th }}$ October 2015].

Muhamad M, Zaman HB, Ahmad A. Virtual laboratory for learning biology: A preliminary investigation. Int J Social Manag Econ Bus Eng. 2010; 4: 379-82.

Prince K, Van De Wiel M, Van Der Vleuten C, Boshuizen H, Scherpbier A. Junior doctors opinions about the transition from medical school to clinical practice: A change of environment. Educ Health. 2004; 17: 323-31.

Rajendran L, Veilumuthu R, Divya J. A study of the effectiveness of virtual lab in e-learning. Int J Comput Sci Eng. 2010; 2: 2173-75.

The complete university guide. Available at: https:// www.thecompleteuniversityguide.co.uk/league-tables/ rankings? $y=2016$ [Accessed on 21 ${ }^{\text {st }}$ January 2016].

Tse MM, Pun SP, Chan MF. Pedagogy for teaching and learning cooperatively on the web: A web-based pharmacology course. Cyber Psychol Behav. 2007; 10: 33-37. 


\section{References for Teaching Modules}

Agrawal RV, Murthy S, Sangwan V, Biswas J. Current approach in diagnosis and management of anterior uveitis. Indian J Ophthalmol. 2010; 58: 11-19.

Asthma initiative of Michigan, 2015. All about nebulizers. Available from: http://getasthmahelp.org/nebulizers.aspx [Accessed on 4th February 2016]

Asthma Society of Canada, 2015. How to use your inhaler. Available at: http://www.asthma.ca/adults/treatment/ spacers.php [Accessed on 8th August 2015]

Asthma UK, 2015. Using your inhaler. Available at: http:// www.asthma.org.uk/ knowledge-bank-treatment-andmedicines-using-your-inhalers\#MeteredDose [Accessed on 8th May 2015]

Available from: http://www.methodspace.com/profiles/ blogs/validating-a-questionnaire [Accessed on 30th August, 2014]

Becton Dickinson (BD), 2015. Insulin injection "At-A-Glance". Available at: http://www.bd.com/resource.aspx? IDX=11314 [Accessed 20th May 2015]

Becton Dickinson (BD), 2015. Improving your insulin injection technique. Available at:http://www.bd.com/ us/diabetes/page. aspx?cat $=7001 \& i d=7264$ [Accessed on $13^{\text {th }}$ May 2015].

Becton Dickinson (BD), 2015. Insulin site rotation template. Available at: http://www.bd.com/resource.aspx?IDX=8079 [Accessed on 21st May 2015].

Becton Dickinson (BD), 2015. Rotating your injection sites. Available at: http://www.bd.com/US/DIABETES/ PAGE.ASPX?CAT $=7001 \& I D=7282$ [Accessed on 21st May 2015].

Bharat Institute of Technology, 2015. Software used in experimental pharmacology. Available at: http:// www.slidesearch.org/slide/software-s-used-inexperimental-pharmacology-cal [Accessed on 29th August 2015].

Bhuiyan HA, Tshering K, Misbahuddin M. Estimation of arsenic in nail using silver diethyldithiocarbamate method. Bangladesh J Pharmacol. 2015; 10: 513-17.

Blunch DN. Virtual chemistry experiments. Available at: $h t t p: / / w w w . c h m . d a v i d s o n . e d u / v c e / s p e c t r o p h o o m e t r y /$ BeersLaw.htmlt [Accessed on 12 ${ }^{\text {th }}$ November, 2015].

Diabetes UK. Steps of using insulin with pen. Available at: https://www.diabetes.org.uk/Guide-to-diabetes/What-isdiabetes/Diabetes-treatments/ [Accessed on 21st May 2015].

Dijksman JA, Khan S. Khan Academy: The world's free virtual school. Presented in focus session APS March Meeting 2011. Available at :http://adsabs.harvard.edu/ abs/2011APS..MARA14006D [Accessed on 22nd January 2016].

Hoag SW, Hussain AS. The impact of formulation on bioavailability: Summary of workshop discussion. J Nutr. 2001; 131: 13895-91S.

Houghton Mifflin Harcourt Publishing Company. American Heritage ${ }^{\circledR}$ Dictionary of the English language. 5th ed. Retrieved from http://www.thefreedictionary.com/ distance+learning [Accessed on 12th March, 2015].

Khan MSH, Hasan M, Clement CK. Barriers to the introduction of ICT into education in developing countries: The example of Bangladesh. Int J Instr. 2012; 5: 62-80.

Labiris NR, Dolovich MB. Pulmonary drug delivery. Part I: Physiological factors affecting therapeutic effectiveness of aerosolized medications. Bri J Clin Pharmacol. 2003; 56: 58899.

MedlinePlus. How to use an inhaler - no spacer. Available at: http:/ / www.nlm.nih.gov/medlineplus/ency / patientinstructions/000041.htm [Accessed on 6th August 2015].

National University of Singapore (NUS). 2013. UV Vis spectroscopy [Online video] Available at: https:// www.youtube.com/watch?v=s5uIVQGFDE4 [Accessed on $12^{\text {th }}$ November 2015].

OER Africa. 2012. Pharmacology: Pharmacological lab procedures: Setting up the Harvard kymograph [online video] Available from: http://www.youtube.com/watch? $\mathrm{v}=\mathrm{Hg} 8$ DejSkuJM [Accessed on 13 $3^{\text {th }}$ May 2015].

Patient Education. 2015. Subcutaneous injection [online video] Available at: https://www.youtube.com/watch? $\mathrm{v}=\mathrm{b} 7 \mathrm{WIr} \_J k g L Q$ [Accessed on 21st May 2015].

Personal communication with Prof. Mir Misbahuddin, Department of Pharmacology, Bangabandhu Sheikh Mujib Medical University (BSMMU), taken on 22nd February, 2015.

Schechter MA, Southerland KW, Feger BJ, Linder D, Ali AA, Njorge L, Milano CA, Bowles DE. An isolated working heart system for large animal models. J Vis Exp. 2014; 88 (51671).

Shah U, Jasani A. UV spectrophotometric and RP-HPLC methods for simultaneous estimation of isoniazid, rifampicin and piperine in pharmaceutical dosage form. Int J Pharm Pharm Sci. 2014; 6: 274-80.

Sydney FYB. Using a Shimadzu spectrophotometer [Online video] Available at: https://www.youtube.com/watch? $\mathrm{v}=\mathrm{ol} \_$YCOPe0Fw [Accessed on $11^{\text {th }}$ November 2015].

Utah Department of Health. How to use an inhaler, 2011. [online video] Available at: https://www.youtube .com/ watch?v=Rdb3p9RZoR4 [Accessed on 27th August 2015].

Virtual classroom. Available at: http://whatis.techtarget.com/ definition/virtual-classroom [Accessed on 22nd February 2015].

WhatIs.com. Virtual learning environment (VLE) or managed learning environment (MLE). Available on: http:// whatis.techtarget.com/definition/virtual-learningenvironment-VLE-or-managed-learning-environment-MLE [Accessed on 15th February 2015].

WikiHow. How to do spectrophotometric analysis. Available at: http://www.wikihow.com/Do-SpectrophotometricAnalysis [Accessed at 15th November 2015].

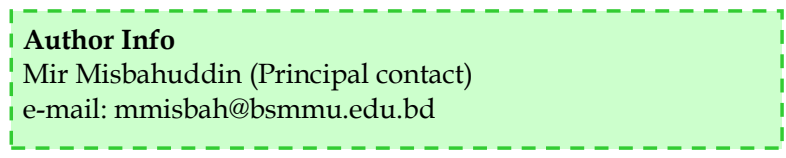

